\title{
Non-routine problem solving and strategy flexibility: A quasi-experimental study
}

\author{
Hüseyin Ozan Gavaz¹, Yeliz Yazgan² and Çiğdem Arslan³ \\ ${ }^{1}$ Ministry of National Education, Turkey (ORCID: 0000-0002-1786-2884) \\ 2Bursa Uludă̆ University, Education Faculty, Turkey (ORCID: 0000-0002-8417-1100) \\ ${ }^{3}$ Bursa Uludă̆ University, Education Faculty, Turkey (ORCID: 0000-0001-7354-8155)
}

\begin{abstract}
This study aims to determine the effect of an instruction dealing with non-routine problem solving on fifth graders' strategy flexibility and success in problem-solving. For this aim, a quasi-experimental pre-testpost-test design without a control group was designed. The sampling method of the research is convenience sampling. There were 65 fifth graders (11-12 years of age) who came from two different classes of a public middle school located in Istanbul/Turkey. The instruction carried out by the first researcher in the students' classrooms lasted ten weeks (20 lesson hours). Pre-test and post-test consisted of eight non-routine problems which can be solved by using guess and check, make a systematic list, work backward, look for a pattern, simplify the problem, and make a drawing strategies. The results showed that instruction that focuses on non-routine problem solving could improve students' strategy flexibility in this area. Besides, non-routine problem-solving instruction was associated with a significant positive improvement in students' problem-solving achievement. Based on these results, some educational implications and suggestions for future studies were discussed.
\end{abstract}

Keywords: Non-routine problems; Problem solving; Problem-solving strategies; Strategy flexibility; Mathematics education

Article History: Submitted 13 February 2020; Revised 22 June 2021; Published online 10 July 2021

\section{Introduction}

Students constantly confront new problems both at school and in their daily lives. Therefore, they need to be flexible beyond knowing and applying various strategies (Silver, 1997). Because the strategy they use in one problem may not work in another, the ability to switch to another strategy is crucial. Hence, many studies have been conducted on flexibility in mathematics education, especially in recent years (e.g. Nguyen et al., 2020; Xu et al., 2017). The fact that the ICMI-East Asia Regional Conferences in Mathematics Education, held in Taiwan in 2018, and one issue of the journal Zentralblatt Didaktik für Mathematik (ZDM) published in 2009 were devoted entirely to flexibility is one of the most important indicators of this. On the other hand, the problems with the greatest potential to improve flexibility are non-routine problems since they are challenging and require higher-order thinking skills (London, 2007). Non-routine problems "adequately address the mathematical knowledge, processes, representational fluency and communication skills that

Address of Corresponding Author

Yeliz Yazgan, PhD, Bursa Uludag University, Education Faculty, Department of Elementary Education, Nilufer, 16059, Bursa, Turkey.

$\triangle$ yazgany@uludag.edu.tr

How to cite: Gavaz, H. O., Yazgan, Y., \& Arslan, Y. (2021). Non-routine problem solving and strategy flexibility: A quasi-experimental study. Journal of Pedagogical Research, 5(3), 40-54. https:// doi.org/10.33902/JPR.2021370581 
our students need for the twenty-first century" (Bonotto \& Dal Santo, 2015, p. 104). Considering these factors, current study attempted to deal with strategy flexibility in conjunction with nonroutine problem solving. The first two sections of this article will provide an outline of these two concepts.

\subsection{Flexibility}

Cognitive flexibility is the ability of a person to change their behavior in the face of changing situations (Star, 2018). This concept is also emphasized and used by mathematics educators. For Demetriou (2004), for example, flexibility refers to the amount of diversity in mental operations and concepts a person has. On the other hand, strategic flexibility is the ability to use multiple strategies and switch strategies flexibly according to task characteristics, personal factors, and environmental impacts (Low \& Chew, 2019). According to this definition, strategic flexibility includes not only knowledge and use of strategies, but also awareness of which strategy will be effective in which situation.

According to Krems (2014), three abilities characterize flexible problem solvers. The first one is considering the various interpretations of data in the problem. The second one is choosing an appropriate representation (concrete, abstract, etc.) for the problem. The third one is changing strategies, which is the important feature of strategy flexibility. Krems (2014) explains this characteristic in more detail as follows:

"A flexible problem solver can change strategies to reflect changes in resources and task demands. These strategy changes might reflect resource usage, or the basic problem-solving approach (e.g., from a more goal-oriented to a more data-oriented approach, from a top-down to a bottom-up, from an exploratory to a confirmatory strategy)." (p.209)

When the studies on strategy flexibility in mathematics education are reviewed, it is seen that this skill is mostly studied in the context of a specific subject area. Algebraic equations (e.g., Star \& Rittle-Johnson, 2008), addition and subtraction (e.g., Selter, 2001), mental calculation and estimation (e.g., Threlfall, 2009) are some of these subject areas. In general, the results of the studies on strategy flexibility have shown that students have an instinct to choose different and appropriate strategies without any intervention and this instinct can (should) be further developed through education, and the factors of easiness, accuracy and fluency are important in strategy selection and development.

In two separate studies, strategy flexibility has been examined by being divided into two different types. In one of them, $\mathrm{Xu}$ et al. (2017) made a distinction between potential and practical flexibility. The authors defined potential flexibility as "knowledge of multiple (standard and innovative) strategies for solving mathematics problems" and practical flexibility as "the ability to implement innovative strategies for a given problem" (p.2). In the other work conducted by Elia et al. (2009), strategy flexibility was classified as intra-task and inter-task. Intra-task flexibility means being able to change strategy while solving a problem. Inter-task flexibility means being able to switch to a different strategy when faced with a new problem situation. In other words, the first one implies changing strategies within problems, while the second one implies changing strategies across problems. This study also draws on inter- and intra-task classification to delve deeper into the strategy flexibility of students.

\subsection{Non-routine Problem Solving}

In the literature related to mathematics education, the most common classification about problem types is the separation into routine and non-routine problems (e.g., Billstein et al., 1996; Martinez, 1998). Routine problems are mostly based on the use of four operations, do not require a process of reasoning or ratiocination, and are of a type whose rules and algorithms required for the solution are previously known (Polya, 1957). For example, the problem, "If each of four students has 12 marbles, how many marbles are there all together?" is a routine problem. Some sources even state that such problems should rather be called "questions" or "exercises" (Krulik \& Rudnick, 1993).

Non-routine problems are problems "for which there is no predictable, well-rehearsed 
approach or pathway explicitly suggested by the task, task instructions, or a worked-out example" (Woodward et al., 2012, p.11). For instance "The students in a class are seated in a circle at regular intervals and given numbers in order. It is given that the students with number 7 and 17 are seated opposite of each other. Then, how many students are there in the class?" problem can be labeled as a non-routine problem. Leading math educators argue that non-routine problems are indispensable for the development of students' problem-solving and reasoning skills (e.g. Polya, 1957; Schoenfeld, 1992).

Non-routine problem-solving strategies can be defined as procedures used to explore, analyze and examine aspects of non-routine problems to indicate pathways to a solution (Nancarrow, 2004). The most famous non-routine problem-solving strategies in the literature are "act it out", "look for a pattern", "make a systematic list", "work backward", "guess and check", "make a drawing or diagram", "write an equation or open sentence", "simplify the problem"," make a table", "eliminate the possibilities"," use logical reasoning", "matrix logic", and "estimation" (Herr \& Johnson, 2002; Leng, 2008; Posamentier \& Krulik, 2008). These strategies do not guarantee a solution but are general and transferable strategies that can be used regardless of a specific subject area (Tiong et al., 2005).

When reviewing studies that deal with non-routine problem solving at primary and secondary school level, four types can be discriminated: Studies examining students' skills and attitudes related to non-routine problem solving without any intervention, studies examining the effects of a given training on students' non-routine problem-solving skills, studies focusing on the place of non-routine problems and strategies in mathematics textbooks and syllabi, and studies elaborating the relationships between non-routine problem-solving skills and other factors such as reading comprehension and mathematical attitude. The results of these studies indicate that i) many students find the non-routine problems are complex and challenging because they are not familiar with this type of problems (e.g., Yeo, 2009), ii) students generally (especially low achievers) have low success in non-routine problem solving (e.g., Elia et al., 2009), iii) non-routine problem-solving training given to students generally increases their success and confidence in solving such problems (e.g. Lee et al., 2014), iv) a very low percentage of problems in textbooks are non-routine problems (e.g. Kolovou et al., 2009), and v) there are other cognitive or affective factors (selfefficacy, reading comprehension, etc.) that have a significant impact on non-routine problemsolving skills (e.g. Öztürk et al., 2020).

\subsection{Literature Review}

Studies conducted by Jausovec (1991) and Dover and Shore (1991) directly examined the flexibility that gifted children exhibited when solving non-routine problems. Jausovec (1991) worked with students aged 17-19 and discussed the link between flexible strategic thinking and problemsolving skills. Dover and Shore (1991) examined the accuracy, speed, flexibility, and metacognitive knowledge of 11-year-old students in non-routine problem solving. The results of these two studies revealed that students with high problem-solving performance exhibited more strategic flexibility than those at medium and low levels and that there was a three-way interaction between giftedness, speed, and flexibility when considered as the metacognitive knowledge control variable.

The aim of the study by Elia et al. (2009) was to probe the strategy use and flexibility of highachieving fourth grade students in non-routine problem solving. To this aim, the authors asked three non-routine problems to the students. They focused on inter-task and intra-task strategy flexibility. The results showed that students' strategy knowledge was limited, and neither type of strategy flexibility was exhibited to a great extent by the students who participated in the study. They also pointed out that in terms of reaching the correct answer, the inter-task flexibility is more decisive than intra-task flexibility.

The goal of Zhang's (2010) research was to observe whether students' problem-solving behaviors will remain consistent between different subject areas and problems that can be solved 
with different strategies. Besides, the researcher aimed to determine the factors affecting students' choices and strategy use in different contexts. One eighth and two ninth grade students participating in the study were asked to solve four non-routine problems. The results revealed inconsistencies in students' problem-solving behaviors across different subject areas and/or strategy use. Consistent with the findings of Elia et. al. (2009) highlighted that intra-task strategy flexibility does not guarantee reaching correct answers.

The study conducted by Arslan and Yazgan (2015) aimed to examine the strategy flexibility of high-achieving sixth, seventh and eighth grade students in non-routine problem solving. The study included four students from each of the aforementioned grade levels. Students worked in pairs to solve four non-routine problems. Based on the intra-task and inter-task strategy flexibility proposed by Elia et al. (2009), the researchers evaluated the students' strategic flexibility according to four criteria (C1: selection and use of the most appropriate strategy, C2: changing strategies when it does not work for the solution of a problem, C3: using multiple strategies for the solution of a problem, and C4: changing strategies between problems). C2 and C3 were connected with intra-task flexibility, while $\mathrm{C} 4$ was pertaining to inter-task flexibility. The results showed that the students were comfortable with choosing and using the appropriate strategy and were able to use more than one strategy together while solving a problem. However, it has also been observed that students have difficulty changing their strategies when their first attempt for a solution is unsuccessful and as they move from problem to problem.

The present study differs from the studies summarized in this section in four points. First, this study has an experimental stance. Second, no distinction was made between students regarding their level of achievement or their intelligence levels. Third, more problems requiring the use of different strategies were employed in this study. Finally, the current study was conducted with more students except that of the study of Elia et al. (2009). Despite these differences, the related studies have also made important contributions to this study. For example, the flexibility types determined by Elia et al. (2009) or the scoring system established by Arslan and Yazgan (2015) were employed in this study. As Star (2018) stated, flexibility has been elaborated in mathematics education only in limited domains such as linear equation solving or addition/subtraction of integers, so whether flexibility in one area can be reflected in different areas has not been examined. One of the main motivations for carrying out this study is to investigate flexibility in another domain that has not been studied much.

\subsection{The Aim and Research Questions}

The current study aims to determine the effect of an instruction dealing with non-routine problem solving on fifth graders' strategy flexibility and problem-solving achievement. In this context, the research questions were determined as follows:

- What is the effect of the non-routine problem-solving instruction on 5th grade students' strategy flexibility?

- What is the effect of the non-routine problem-solving instruction on 5th grade students' problem-solving achievement?

\section{Method}

\subsection{Research Design}

A quasi- experimental pre-test - post-test design without a control group was used in the study. This design mainly "reports on the value of a new teaching method or interest aroused by some curriculum innovation" (Cohen et al., 2007, p. 283). The effect of the experiment is tested by working on a single group. Measurements of the same subjects related to the dependent variable are obtained by pre-test before the experiment and post-test after the experiment. There is no randomness or matching in this pattern, which is why it is classified as quasi-experiment (Cohen et al., 2007). 


\subsection{Sampling}

Convenience sampling was used to select participants. The basis of convenience sampling is the selection of easily accessible participants at the time of the research (Fraenkel et al., 2012). In the context of this study, the first researcher chose two of the courses he taught as the experimental group due to accessibility. As a result of getting to know the pupils on a personal level, he was able to track their progress in more depth. He was also more equipped at other aspects, such as how to build a learning environment for non-routine problem solving, thanks to his doctoral studies in mathematics education.

\subsection{Participants}

There were 65 fifth graders (11-12 years of age) in the experimental group. As noted earlier, these students came from two different classes of a public middle school located in Istanbul/Turkey. In one class, there were 32 students, while the other one included 33 students. Thirty-nine of the students were boys, and 26 were girls. Based on their math teacher's statement (the first researcher), students' mathematics achievement was generally at the average level. Besides, students had no special instruction on non-routine problems until the current study was carried out.

\subsection{Instruments}

Pre-test and post-test consisted of eight non-routine problems (see Appendix for some samples) which can be solved by using guess and check, make a systematic list, work backward, look for a pattern, simplify the problem, and make a drawing ${ }^{1}$ strategies. Possible strategies for each problem in pre-test and post-test are listed in Table 1.

Table 1

Possible strategies for each problem in pre-test and post-test

\begin{tabular}{|c|c|c|}
\hline $\begin{array}{l}\text { Numbers of problems in pre- } \\
\text { test and post-test }\end{array}$ & Strategies & Definition of the strategies \\
\hline 1,2 & Make a systematic list & $\begin{array}{l}\text { All possible situations are written down in a } \\
\text { systematic way to reach the solution. }\end{array}$ \\
\hline 3,4 & Work backward & $\begin{array}{l}\text { The solution process starts with the last situation } \\
\text { given in the problem. Then, all the steps in the } \\
\text { problem are reversed to reach the original state. }\end{array}$ \\
\hline 5,6 & Guess and check & $\begin{array}{l}\text { The process of solving the problem starts with a } \\
\text { guess, and if the guess is not correct, another guess } \\
\text { is made. This process continues until the correct } \\
\text { answer is reached. }\end{array}$ \\
\hline \multirow[t]{3}{*}{7,8} & Look for a pattern & $\begin{array}{l}\text { The problem is solved by noticing a pattern or rule } \\
\text { among the numbers or figures given in the problem. }\end{array}$ \\
\hline & Simplify the problem & $\begin{array}{l}\text { Simpler versions of the given problem are solved } \\
\text { first. Then a pattern is noticed from these solutions, } \\
\text { and this pattern is adapted to the original problem. }\end{array}$ \\
\hline & Make a drawing & $\begin{array}{l}\text { Visual aids such as figures and diagrams are used to } \\
\text { solve the problem. }\end{array}$ \\
\hline
\end{tabular}

As can be seen from Table 1, the same number of questions in which the same strategy can be used were included in both the pre-test and post-test. These questions were created similar in structure to each other. For example, looking at the first problems in the pre-test (A restaurant's menu includes tomato soup and French fries as starters, and steak, mashed potatoes, and fried fish as main courses. How many different menus can you create, provided you choose one starter and one main course?)

1Problem examples that require the use of these strategies are given through pre and post-test problems represented both in the text and the appendix. Readers can understand which question is for which strategy by looking at the explanations given in Table 1 . 
and post-test (A pizzeria offers five toppings: olives, cheese, mushrooms, tomatoes, salami. Süleyman wants to order pizza with only two toppings. In how many different ways can Süleyman choose the toppings for his pizza?), it is seen that both require making a choice among the options presented. However, the contexts of the questions (restaurant in the first and pizzeria in the other) are different.

Non-routine problems used in the pre-test, post-test, and instructional process were selected from the pool created by compiling from different sources. While making these selections, the authors took the following criteria: suitability for the student's grade level, clarity of the problem text and context for the student, suitability for strategy use. Additionally, the pre- and post-test questions had been asked to students within the scope of a project carried out by Yazgan et al. (2013) and reviewed in terms of language and difficulty. Therefore, the authors did not need a validity study in this respect.

\subsection{Process}

The instruction was carried out by the first researcher in the students' own classrooms and within the scope of the elective "Mathematics Applications" course. During the instruction that lasted ten weeks (20 lesson hours), students worked on 40 non-routine problems that can be solved by using the strategies listed in Table 1. Each of the first six weeks was allocated to six strategies. During these weeks, students solved problems related to the same strategy for two class hours. Here, it was aimed for the student to grasp the logic of the strategy based on the common points of the solved problems. In the remaining four weeks, no distinction was made between strategies, and questions that could be solved with different strategies were given to the students in a mixed manner. Names or principles of the non-routine problem-solving strategies were not directly introduced to the students; instead, students were just faced with problems.

The process followed for each problem in the instruction was as follows: First, the problem to be solved was distributed to the students in written form. The students worked on the problem for 10-15 minutes on their own. Meanwhile, the first researcher walked among the students and made an explanation when there were any unclear points about the problem. When the time was up, the students' solution papers were collected, followed by a class discussion. During class discussion, students wrote and discuss their solutions on the board, compared different solutions, and could easily interact with each other. The situations in which the same problem can be solved with different strategies, strategies are used in combination, or the chosen strategy was changed since it did not work were especially emphasized. Throughout the instruction, the first researcher challenged students to think flexibly by asking questions as follows: "Could the problem be solved in another way?", "Does this problem look like the ones you have solved before?", "Can you solve this problem with the same method?", "Did the way you chose work?", "Why do you think it didn't work?" etc. Thus, students were also encouraged to think aloud.

\subsection{Data Analysis}

Two different types of scoring were used to analyze data in the current study. First, pre-test and post-test papers were examined based on four criteria established by Arslan and Yazgan (2015). The authors used these criteria in this study because the scoring system was made according to its purpose, namely based on non-routine problem solving, and was sufficiently detailed and available. Each criterion was scored as 0, 1, 2 and 3 (see Table 2 for details) by the first author. Thus, every student had a total flexibility score for each test between 0 and 12 . During this procedure, the main focus was on the correctness of reasoning and strategy use instead of right answer. Besides, scoring was not made separately for each question. Instead, each of the pre-test and post-test papers was examined as a whole. The last two problems in each test were especially fundamental for scoring C3 (using multiple strategies for the solution of a problem).

In order to test the reliability of this coding system, Cronbach alpha coefficients were calculated based on the criterion scores obtained from the pre- and post-test and found as .64 and .79, respectively. Considering that the values found are close to the desired value (.70), it can be stated that the scoring system used for the criteria is reliable. 
Table 2

Scoring system for each criterion

\begin{tabular}{|c|c|c|c|c|}
\hline $\begin{array}{l}\stackrel{0}{0} \\
\ddot{n}\end{array}$ & $\begin{array}{c}\text { C1 } \\
\text { (selection and use of } \\
\text { the most appropriate } \\
\text { strategy) }\end{array}$ & $\begin{array}{l}\text { C2 } \\
\text { (changing strategies } \\
\text { during the solution of a } \\
\text { problem) }\end{array}$ & $\begin{array}{c}\text { C3 } \\
\text { (using multiple } \\
\text { strategies for the } \\
\text { solution of a problem) }\end{array}$ & $\begin{array}{c}\text { C4 } \\
\text { (changing strategies } \\
\text { between problems) }\end{array}$ \\
\hline 0 & $\begin{array}{l}\text { No strategy use or no } \\
\text { answer }\end{array}$ & $\begin{array}{l}\text { No strategy use or no } \\
\text { answer }\end{array}$ & $\begin{array}{l}\text { Using only one strategy } \\
\text { or no answer }\end{array}$ & $\begin{array}{l}\text { No strategy change } \\
\text { across problems or no } \\
\text { answer }\end{array}$ \\
\hline 1 & $\begin{array}{l}\text { Selection and use of } \\
\text { appropriate strategies } \\
\text { for one or two } \\
\text { problems }\end{array}$ & $\begin{array}{l}\text { Changing strategies } \\
\text { within one or two } \\
\text { problems }\end{array}$ & $\begin{array}{l}\text { Enterprise for using } \\
\text { multiple strategies for } \\
\text { one problem }\end{array}$ & $\begin{array}{l}\text { Using two different } \\
\text { strategies for different } \\
\text { problems }\end{array}$ \\
\hline 2 & $\begin{array}{l}\text { Selection and use of } \\
\text { appropriate strategies } \\
\text { for three-five problems }\end{array}$ & $\begin{array}{l}\text { Changing strategies } \\
\text { within three-five } \\
\text { problems }\end{array}$ & $\begin{array}{l}\text { Enterprise for using } \\
\text { multiple strategies for } \\
\text { two problem }\end{array}$ & $\begin{array}{l}\text { Using three different } \\
\text { strategies for different } \\
\text { problems }\end{array}$ \\
\hline 3 & $\begin{array}{l}\text { Selection and use of } \\
\text { appropriate strategies } \\
\text { for six-eight problems }\end{array}$ & $\begin{array}{l}\text { Changing strategies } \\
\text { within six-eight } \\
\text { problems }\end{array}$ & $\begin{array}{l}\text { Exact use of multiple } \\
\text { strategies for two } \\
\text { problem }\end{array}$ & $\begin{array}{l}\text { Using four or more } \\
\text { strategies for different } \\
\text { problems }\end{array}$ \\
\hline
\end{tabular}

Figure 1 shows one sample of student answers to the question of "When tossing two dice, how many different sums can show up?". This question was the second problem of post-test. Although this student made one calculation error $(6+6=18)$ and did not write one of the possible sums $(1+$ $1=2$ ), he chose and applied the appropriate strategy (make a systematic list) for this question.

Figure 1

One sample of student answer to the second problem of post-test

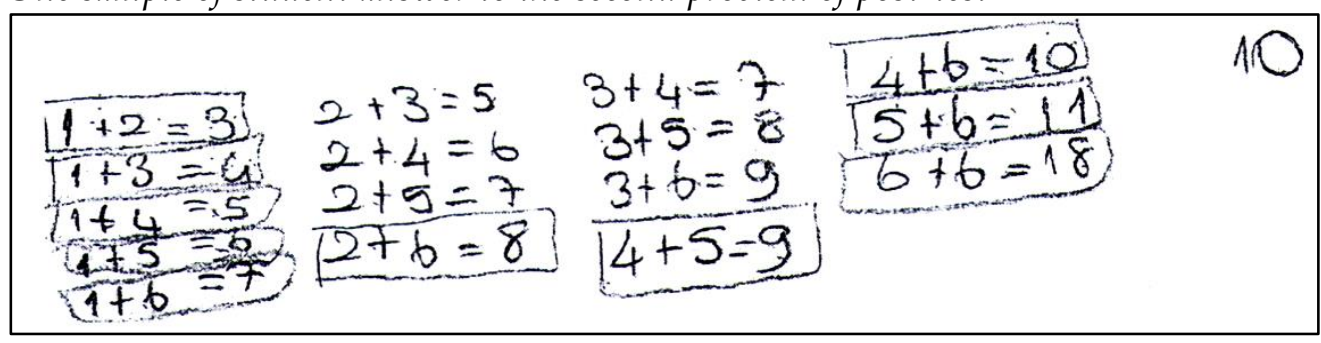

The second type of scoring focused on whether the students reached the correct solution or not. This time, students' answers to each question were scored as 0 (wrong answer or no answer), 1 (partially correct answer), and 2 (correct answer) by the first author. According to this scoring, the students got scores between 0 and 16 in terms of success in reaching the correct answer. For the reliability of this coding system, Cronbach alpha coefficients were computed based on each problem's correctness score and found as .763 and .853 for pre- and post-test, respectively. These values also show that the scoring system used for correctness is reliable.

Figure 2 shows examples of answers given to the fourth problem (The number of chickens in a poultry farm increases every month to 3 times the previous one. If after three months the number of chickens on the farm is 189, how many chickens were there in the beginning?) in the pre-test which were scored as 2,1 , and 0 , respectively. 
Figure 2

Sample student answers scored as 2, 1, and 0 based on correctness

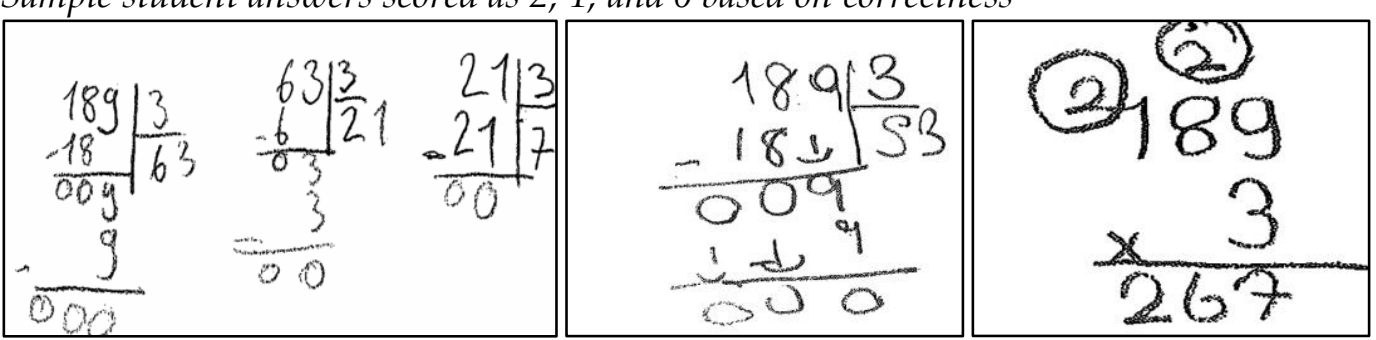

To ensure inter-coder reliability, the second researcher re-scored the pre-test and post-test papers of ten randomly selected students in terms of both scoring systems. As a result, there was no contradiction between the first researcher's and the second researcher's scores.

To analyze data, first descriptive statistics were run for the criterion and total flexibility scores and total correctness scores. Results of Kolmogorov-Smirnov tests and kurtosis and skewness coefficients (Can, 2019) were examined to decide whether all data obtained from the pre- and posttest were normally distributed. Since none of the scores were normally distributed, the Wilcoxon Signed-Rank test was used to test whether there was a significant difference between the pre-test and post-test scores.

\section{Findings}

\subsection{Findings on the First Research Question}

The frequencies of the criteria-based scores obtained by students in the pre-and post-test are presented in Table 2 and illustrated in Figure 3 to see students' overall progress in each criterion as well as to compare the frequencies of pre-test and post-test scores.

Table 3

Frequencies of the pre- and post-test scores

\begin{tabular}{cccccccccc}
\hline & \multicolumn{1}{c}{ Pre-test } & \multicolumn{5}{c}{ Post-test } \\
\cline { 2 - 11 } & $\mathrm{N}$ & 0 & 1 & 2 & 3 & 0 & 1 & 2 & 3 \\
\hline $\mathrm{C} 1$ & 65 & 33 & 26 & 6 & 0 & 10 & 26 & 19 & 10 \\
$\mathrm{C} 2$ & 65 & 63 & 2 & 0 & 0 & 57 & 7 & 1 & 0 \\
$\mathrm{C} 3$ & 65 & 62 & 3 & 0 & 0 & 19 & 24 & 20 & 2 \\
$\mathrm{C} 4$ & 65 & 29 & 32 & 3 & 1 & 9 & 27 & 19 & 10 \\
\hline
\end{tabular}

The values in Table 3 and Figure 3 show that the number of students who got 0 points decreased from the pre-test to the post-test, whereas the number of students who got 1 and 2 points increased. The number of students who scored 3 points in the post-test is not very high, but compared to the pre-test, there is an increase in this respect, except for $\mathrm{C} 1$. In general, it is noteworthy that the frequencies related to $\mathrm{C} 1, \mathrm{C} 3$, and $\mathrm{C} 4$ became closer to the normal distribution in the post-test.

Descriptive statistics computed for pre- and post-test based on criterion and total flexibility scores are represented in Table 4. 
Figure 3

Graphs of pre- and post-test scores

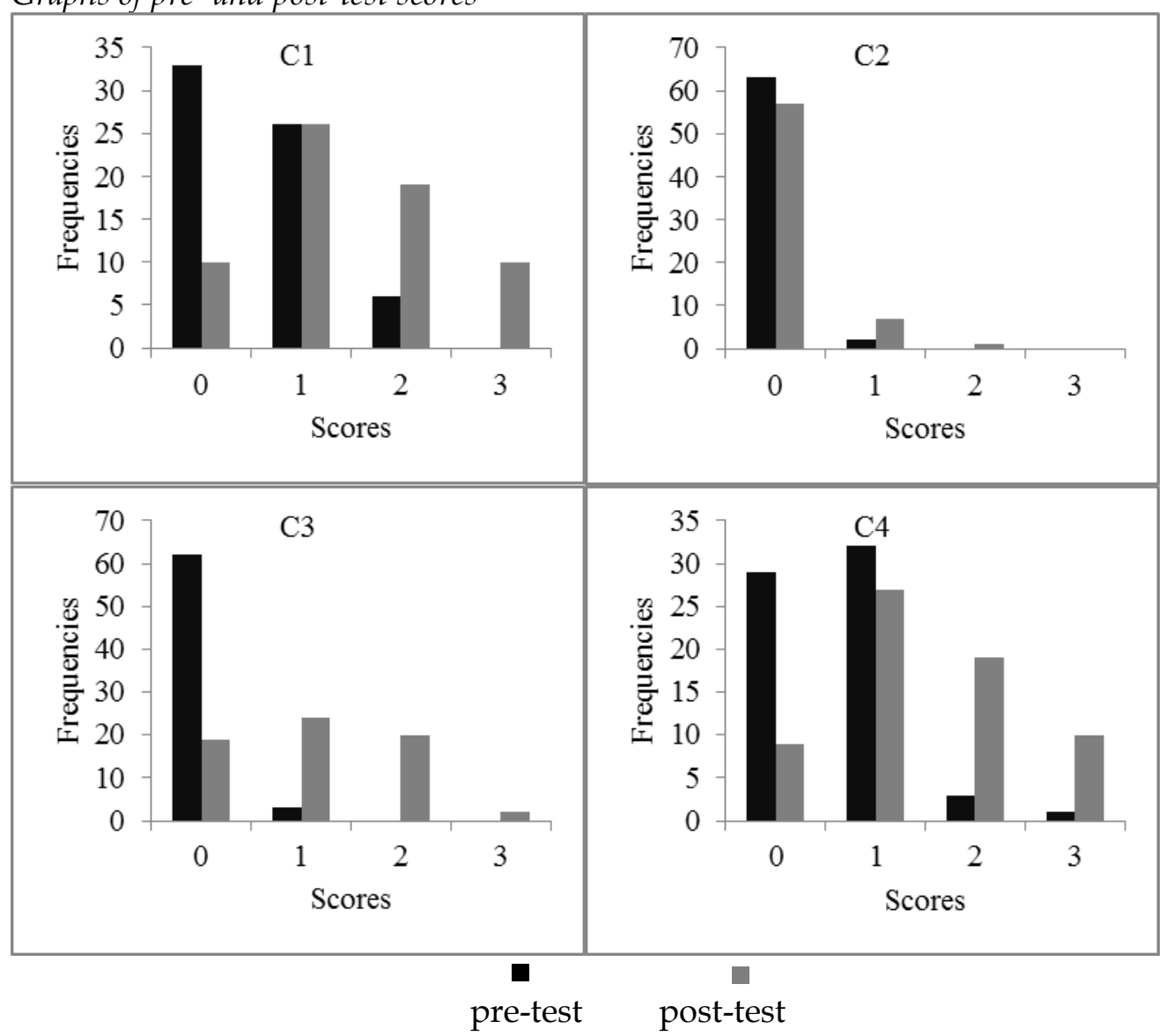

Table 4

Descriptive statistics of pre-test and post-test based on criterion and total flexibility scores

\begin{tabular}{|c|c|c|c|c|c|c|c|c|c|}
\hline & \multirow[b]{2}{*}{$N$} & \multicolumn{4}{|c|}{ Pre-test } & \multicolumn{4}{|c|}{ Post-test } \\
\hline & & Min & $\operatorname{Max}$ & Mean & $S D$ & Min & $\operatorname{Max}$ & Mean & $S D$ \\
\hline $\mathrm{C} 1$ & 65 & 0 & 2 & .585 & .659 & 0 & 3 & 1.446 & .936 \\
\hline $\mathrm{C} 2$ & 65 & 0 & 1 & .031 & .174 & 0 & 2 & .139 & .390 \\
\hline C3 & 65 & 0 & 1 & .046 & .212 & 0 & 3 & 1.077 & .853 \\
\hline $\mathrm{C} 4$ & 65 & 0 & 3 & .631 & .651 & 0 & 3 & 1.46 & .920 \\
\hline Total & 65 & 0 & 6 & 1.292 & 1.343 & 0 & 11 & 4.121 & 2.534 \\
\hline
\end{tabular}

When the values in Tables 4 are taken into account, the following remarkable results can be summarized: In the pre-test, criterion and total flexibility scores were below average. In the posttest, it was determined that each score had increased. Except for C2 (changing techniques during the solution of a problem), all the other scores improved after the instruction. Another striking result was that the pre-test and post-test rankings of criterion in terms of mean did not alter. It is also noteworthy that C3 (using multiple strategies for the solution of a problem) was the criterion with the highest mean increase among the criteria.

Wilcoxon signed-rank test results based on criterion and total flexibility scores are presented in Table 5 . 
Table 5

Wilcoxon signed-rank test results related to criterion and total flexibility scores

\begin{tabular}{llccccc}
\hline & Post-test-pre-test & $N$ & Mean rank & Sum of ranks & $z$ & $p$ \\
\hline \multirow{4}{*}{ C1 } & Negative ranks & 3 & 16.50 & 49.50 & -5.61 & $.00^{*}$ \\
& Positive ranks & 43 & 23.99 & 1031.50 & & \\
& Ties & 19 & & & & \\
& Negative ranks 2 & 2 & 5.00 & 10.00 & -1.94 & .052 \\
& Positive ranks & 8 & 5.63 & 45.00 & & \\
& Ties & 55 & & & & \\
& Negative ranks 3 & 0 & .00 & .00 & -5.94 & $.00^{*}$ \\
& Positive ranks & 44 & 22.50 & 990.00 & & \\
& Ties & 21 & & & & \\
\multirow{5}{*}{ C4 } & Negative ranks & 4 & 19.50 & 78.00 & -5.65 & $.00^{*}$ \\
& Positive ranks & 45 & 25.49 & 1147.00 & & \\
& Ties & 16 & & & & \\
& Negative ranks & 5 & 9.20 & 46.00 & -6.36 & $.00^{*}$ \\
& Positive ranks & 54 & 31.93 & 1724.00 & & \\
\hline
\end{tabular}

*Significant at .05 level

According to results in Table 5, the instruction on non-routine problem solving had a significant positive effect on students' C1 (selection and use of the most appropriate strategy), C3 (using multiple strategies for the solution of a problem), C4 (changing strategies between problems) and total flexibility scores. The increase in the scores of $\mathrm{C} 2$ (changing strategies when it does not work for the solution of a problem) from pre-test to post-test and related positive ranks showed that students also progressed in terms of this criterion. However, this increase was not found to be statistically significant.

To support the quantitative results qualitatively, some examples of student responses from the posttest are presented in Figures 4, 5, and 6.

Figure 4

A student response to the third problem in the post-test

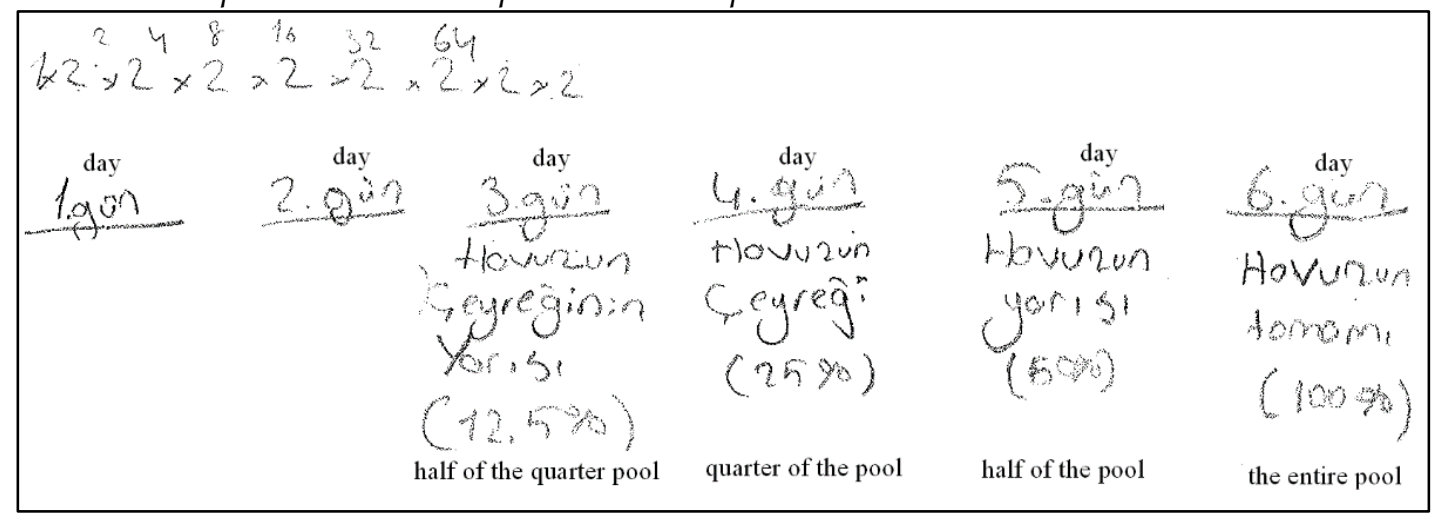

Student response to the problem (A patch of lily pads doubles its size each day after it starts growing in a pond. If a pond was covered entirely just today, what percent of it was covered in lily pads three days ago?) in the posttest as presented in Figure 4 shows that the student first tried to reach the solution using the powers of two, but when it didn't work, he got the right answer using the work backward strategy. Thus, he exhibited the ways in accordance with both C1 and C2. 
Figure 5

A student response to the fourth problem in the post-test

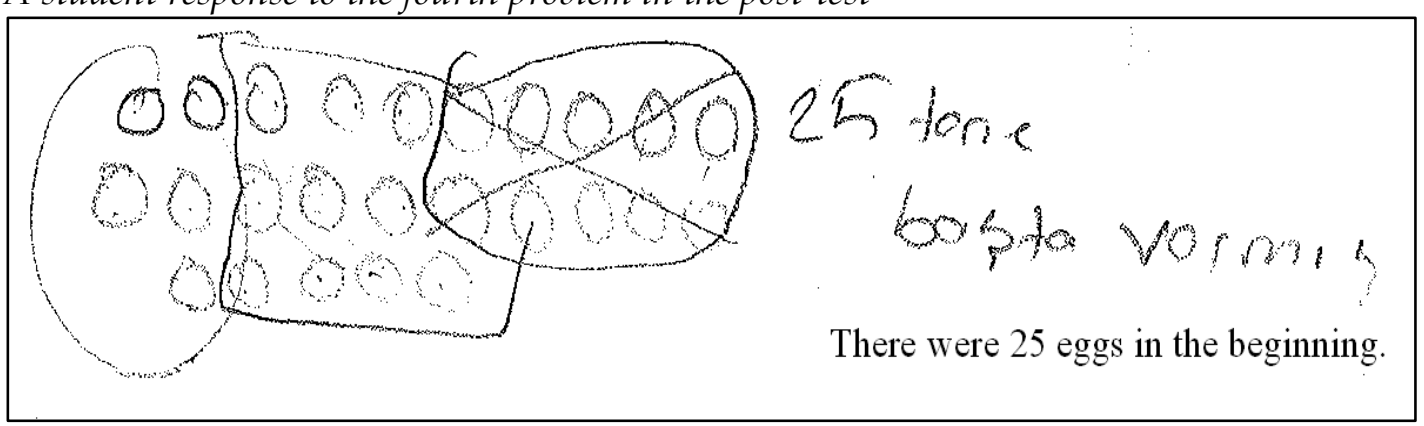

Figure 5 shows the response of the same student to the fifth problem (Buse broke 2/5 of her eggs. She sold 2/3 of the rest. If she has five eggs left, how many eggs were there in the beginning?) in the posttest. In this solution, the student applied a different strategy (make a drawing) than in the previous question. This student was able to easily switch between strategies not only in these two questions in the post-test, but also in other questions. As a result, he got the maximum score from the C4 (changing strategies between problems) in the post-test.

Figure 6

A student response to the eighth problem in the post-test

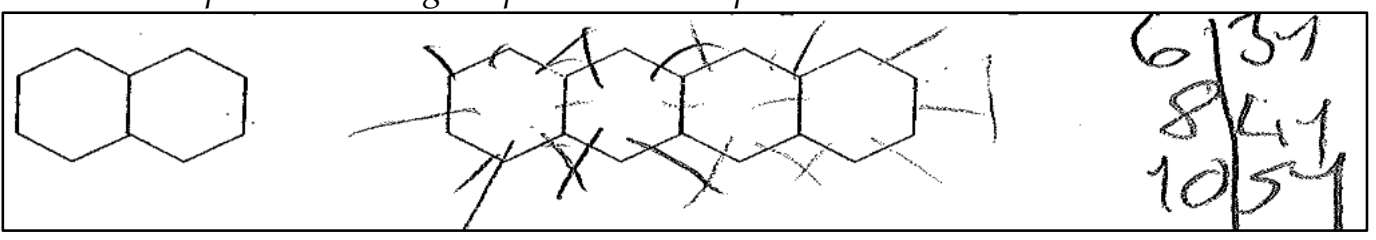

Another student's response to the eighth problem in the post-test (see Appendix, item d) is a good example for C3 (using multiple strategies for the solution of a problem). This student used look for a pattern and simplify the problem strategies together to reach the solution.

\subsection{Findings on the second research question}

Descriptive statistics and Wilcoxon signed-rank test results related to correctness scores can be seen in Tables 6 and 7. From the values in Table 6, it can be inferred that students' correctness scores increased from pre-test to post-test. However, considering that the maximum score (16), the correctness scores are below the average even after the intervention.

Table 6

Descriptive statistics of pre-and post-test based on correctness scores

\begin{tabular}{lccccc}
\hline & $N$ & Min & Max & Mean & $S D$ \\
\hline Pre-test & 65 & 0 & 13 & 2.75 & 2.64 \\
Post-test & 65 & 0 & 15 & 5.6 & 4.47 \\
\hline
\end{tabular}

Table 7

Wilcoxon signed-rank test results related to correctness scores

\begin{tabular}{lccccc}
\hline Post-test-pre-test & $N$ & Mean rank & Sum of ranks & $z$ & $p$ \\
\hline Negative ranks & 9 & 21.72 & 195.50 & -5.31 & $.00^{*}$ \\
Positive ranks & 51 & 32.05 & 1634.50 & & \\
Ties & 5 & & & & \\
\hline
\end{tabular}

*Significant at .05 level

The results in Table 7 refer that designing non-routine problem-solving instruction provided with a significant improvement in students' achievement. However, as stated earlier, this improvement was not enough for students to rise above the average in terms of reaching the 
correct answer.

\section{Discussion and Conlusion}

When students face appropriately selected and challenging problems, they will be more flexible in exploring mathematical ideas and trying alternative solutions (National Council of Teachers of Mathematics [NCTM], 2000). Non-routine problems carry the above-mentioned "challenging" feature to a significant extent. This is the most important reason for using non-routine problems in this study. On the other hand, in our era of rapid change, one of the important goals of education is to develop flexible problem-solving skills (Kalyuga et al., 2010). Therefore, one of the important components of this study is strategy flexibility.

The purpose of the first research question was to examine whether strategy flexibility in nonroutine problem solving could be improved through education. The results showed that an instruction that focuses on non-routine problem solving could improve students' strategy flexibility in this area. This is the result that distinguishes this study from other related studies and contributes to the field. As explained in the method part, the students had the opportunity to share different solutions with their friends and teachers during the instruction. In addition, they were able to discuss why the chosen strategy did not work and what could be chosen instead. It can be said that this environment supports strategy development. The students in the study had rarely or never encountered non-routine problems before. Even if they had solved any non-routine problem, they had no opportunity to discuss solutions. During the instruction, they solved many non-routine problems and unwittingly expanded their knowledge of the strategies used to solve these problems (not even knowing the strategies' names). It can be stated that the scores of $\mathrm{C} 1$ (selection and use of the most appropriate strategy), C3 (using multiple strategies for the solution of a problem) and C4 (changing strategies between problems) increased positively and significantly, as the strategy vocabulary developed. A statistically significant increase was not observed only in C2 (changing strategies during the solution of a problem) scores. However, considering how close the significance value related to this criterion is (.052) to .05, it can be concluded that the students are also open to improvement in terms of this criterion, but maybe they need a little more time. As stated by Zhang (2010), intra-task strategic flexibility is largely influenced by individuals' tendencies to use certain strategies. For this reason, many students avoid changing the strategy and stop solving the problem when their preferred strategy doesn't work. The same situation manifests itself in the low scores of $\mathrm{C} 2$ (changing strategies during the solution of a problem) in this study.

Another striking point here is that even after the instruction, the criteria and total flexibility scores do not exceed the average. Elia et al. (2009) and Arslan and Yazgan (2015) have also found that students have low intra-task and inter-task flexibility. It is understood from this that students have difficulty in breaking the effects of traditional mathematics education that focuses on routine problems.

The second research problem was about whether the students' problem-solving achievement would increase after the non-routine problem-solving instruction. The relevant descriptive statistics and Wilcoxon Rank Test results indicate that the students showed a statistically significant improvement from the pre-test to the post-test in this respect. Even so, students exhibited below-average success in reaching the correct answer even after the training. Given the factors mentioned in the previous two paragraphs (students not being familiar with non-routine problems, having difficulty changing strategies, etc.), this is an expected result. However, when the results on the two research questions are evaluated together, the following point draws attention: Students' both strategy flexibility and problem-solving achievement increased after the instruction given. This may indicate the positive relationship between strategy flexibility and achievement in problem solving, although it is not specifically addressed in this study. From this point of view, Jausovec (1991) and Dover and Shore (1991) also reached similar results. 
The results of the present study also have some implications for teaching of mathematics. The students' low averages in terms of both strategy flexibility and correctness show that non-routine problems and solution strategies should be included more in mathematics curricula, learning environments, and textbooks. Strategy flexibility is a more comprehensive skill that requires not only knowledge of strategy but also the ability to chose the beststrategy and switch between them. In this context, in-service and pre-service teacher education programs should raise awareness about strategy flexibility and how to create a learning environment that fosters this skill.

Several limitations of this study should be considered. First, students would have had more opportunities to progress in non-routine problem solving and approach flexibility if the teaching provided in our study had been more extended. This issue can be addressed in future experiments, and outcomes can be observed. Second, the participants of this paper composed of fifth graders. Similar studies to be conducted at different grade levels may provide more robust and generalizable results. Although we used relatively more problems in this study compared to the existing studies in the literature, the students' written responses and their development in reaching the correct answer in terms of problem solving were examined. In other words, we were unable to examine the students' thinking processes during the solution in a detailed way. This situation especially made it difficult for us to score C2 (changing strategies during the solution of a problem). Because in this study, C2 refers to the use of a different strategy before reaching a solution in cases where the chosen strategy does not work or a more useful strategy is noticed. However, approaching the same problem with another strategy after finding the answer can be considered as another indicator of in-task strategy flexibility. We were unable to ask students to validate their responses using a different strategy. These deficiencies can be remedied in a further study involving more qualitative techniques such as interview or observation. As a final remark, future studies are recommended to survey with the participation of a larger sample to examine whether a relationship exists between non-routine problem-solving performance and strategy flexibility.

\section{References}

Arslan, C. \& Yazgan, Y. (2015). Common and flexible use of mathematical non routine problem solving strategies. American Journal of Educational Research, 3(12), 1519-1523. https://doi.org/10.12691/education3-12-6

Billstein, R., Libeskind, S., \& Lott, J. W. (1996). A Problem solving approach to mathematics for elementary school teachers. Addison Wesley Longman Inc.

Bonotto, C., \& Dal Santo, L. (2015). On the relationship between problem posing, problem solving and creativity in the primary school. In F. Singer, N. F. Ellerton ve J. Cai (Ed.), Mathematical problem posing: From research to effective practice (pp. 103-123). Springer.

Can, A. (2019). SPSS ile bilimsel araştırma sürecinde nicel veri analizi [Quantitative data analysis in scientific research process with SPSS]. Pegem.

Cohen, L., Manion, L., \& Morrison, K. (2007). Research methods in education. Routledge.

Demetriou, A. (2004). Mind intelligence and development: A cognitive, differential, and developmental theory of intelligence. In A. Demetriou \& A. Raftopoulos (Eds.), Developmental change: Theories, models and measurement (pp. 21-73). Cambridge University Press.

Dover, A., \& Shore, B. M. (1991). Giftedness and flexibility on a mathematical set-breaking task. Gifted Child Quarterly, 35(2), 99-105. https://doi.org/10.1177/001698629103500209

Elia, I., van den Heuvel-Panhuizen, M., \& Kolovou, A. (2009). Exploring strategy use and strategy flexibility in non-routine problem solving by primary school high achievers in mathematics. ZDM, 41(5), 605-618. https://doi.org/10.1007/s11858-009-0184-6

Fraenkel, J. R., Wallen, N. E., \& Hyun, H. H. (2012). How to design and evaluate research in education (8th ed.). McGraw-Hill.

Herr, T., \& Johnson, K. (2002). Problem-solving strategies: Crossing the river with dogs. Key Curriculum Press.

Jausovec, N. (1991). Flexible strategy use: A characteristic of gifted problem solving. Creativity Research Journal, 4(4), 349-366. https://doi.org/10.1080/10400419109534411 
Kalyuga, S., Renkl, A., \& Paas, F. (2010). Facilitating flexible problem solving: A cognitive load perspective. Educational Psychology Review, 22(2), 175-186. https://doi.org/10.1007/s10648-010-9132-9

Kolovou, A., van den Heuvel-Panhuizen, M., \& Bakker, A. (2009). Non-routine problem solving tasks in primary school mathematics textbooks - a needle in a haystack. Mediterranean Journal for Research in Mathematics Education 8(2), 31-68.

Krems, J. F. (2014). Cognitive flexibility and complex problem solving. In P. A. Frensch and J. Funke (Eds.), Complex Problem Solving the European Perspective (pp. 206-223). Psychology Press.

Krulik, S., \& Rudnick, J. A. (1993). Reasoning and problem solving: A handbook for elementary school teachers. Allyn and Bacon.

Lee, N. H., Yeo, J. S. D., \& Hong, S. E. (2014). A metacognitive based instruction for primary four students to approach non-routine mathematical word problems. ZDM, 46(3), 465-480. https:// doi.org/10.1007/s11858-014-0599-6

Leng, N. W. (2008). Problem solving heuristics for primary school mathematics: A comprehensive guide. Prentice Hall.

London, R. (2007). What is essential in mathematics education: A holistic viewpoint. MSOR Connections, 7(1), 30-34.

Low, C. S., \& Chew, C. M. (2019). Strategy flexibility in mathematics education. In C. S. Lim, C. M. Chew \& B. Sriraman (Eds.), Mathematics Education from an Asian Perspective (Contemporary Research and Practice Series) (pp. 85-105). USM Press.

Martinez, M. E. (1998). What is problem solving?. The Phi Delta Kappan, 79(8), 605-609.

Nancarrow, M. (2004). Exploration of metacognition and non-routine problem-based mathematics instruction on undergraduate student problem-solving success (Publication No. 3137375.) [Doctoral dissertation, The Florida State University]. ProQuest Dissertations Publishing.

National Council of Teachers of Mathematics (2000). Principles and standards for school mathematics. Author.

Nguyen, H. A., Guo, Y., Stamper, J., \& McLaren, B. M. (2020, July). Improving students' problem-solving flexibility in non-routine mathematics. In I. Bittencourt, M. Cukurova, K. Muldner, R. Luckin, \& E. Millán (Eds), Artificial Intelligence in Education (pp. 409-413). Springer.

Öztürk, M., Akkan, Y., \& Kaplan, A. (2020). Reading comprehension, mathematics self-efficacy perception, and Mathematics attitude as correlates of students' non-routine mathematics problem-solving skills in Turkey. International Journal of Mathematical Education in Science and Technology, 51(7), 1042-1058. https:// doi.org/10.1080/0020739X.2019.1648893

Polya, G. (1957). How to solve it: A new aspect of mathematical method (2nd ed.). Princeton University Press.

Posamentier, A. S., \& Krulik, S. (2008). Problem solving strategies for efficient and elegant solutions, grades 6-12: A resource for the mathematics teacher. Corwin Press.

Schoenfeld, A. H. (1992). Learning to think mathematically: Problem-solving, metacognition and sensemaking in mathematics. In D. Grouws (Ed.), Handbook for Research on Mathematics Teaching and Learning (pp. 334-370). Mac Millian.

Selter, C. (2001). Addition and subtraction of three-digit numbers: German elementary children's success, methods and strategies. Educational Studies in Mathematics, 47(2), 145-173. https://doi.org/10.1023/a:1014521221809

Silver, E. A. (1997). Fostering creativity through instruction rich in mathematical problem solving and problem posing. ZDM, 29(3), 75-80. https:// doi.org/10.1007/s11858-997-0003-x

Star, J. (2018). Flexibility in mathematical problem solving: The state of the field. In F. J. Hsieh, (Ed.) Proceedings of the 8th ICMI-East Asia Regional Conference on Mathematics Education: Vol. 1 (pp. 15-25). EARCOME8-National University of Taiwan.

Star, J. R., \& Rittle-Johnson, B. (2008). Flexibility in problem solving: The case of equation solving. Learning and Instruction, 18(6), 565-579. https:// doi.org/10.1016/j.learninstruc.2007.09.018

Threlfall, J., (2009). Strategies and flexibility in mental calculation. ZDM, 41(5), 541-555. https://doi.org/10.1007/s11858-009-0195-3

Tiong, J. Y. S., Hedberg, J. G., \& Lioe, L. T. (2005). A metacognitive approach to support heuristic solution of mathematical problems. Proceedings of the Redesigning Pedagogy: Research, Policy, Practice Conference. Singapore National Institute of Education.

Woodward, J., Beckmann, S., Driscoll, M., Franke, M., Herzig, P., Jitendra, A., Ogbuehi, P. (2012). Improving mathematical problem solving in grades 4 through 8: A practice guide (NCEE 2012-4055). National Center for Education Evaluation and Regional Assistance, Institute of Education Sciences, U.S. Department of Education. 
Xu, L., Liu, R., Star, J. R., Wang, J., Liu, Y., \& Zhen, R. (2017). Measures of potential flexibility and practical flexibility in equation solving. Frontiers in Psychology, 8, 1368. https://doi.org/10.3389/fpsyg.2017.01368

Yazgan, Y., Arslan, Ç., Tapan, M. S., Memnun, D. S., Akkaya, R., Çelebioğlu, B., \& Yılmaz, A. (2013). Ilköğretim ve lise öğrencilerinin sıradışı problemleri çz̈zme yeterlilikleri [Primary and high school students' nonroutine problem solving qualifications] (Project No. E(U)-2009/49). Bursa Uludağ University, Scientific Research Projects.

Yeo, K. K. J. (2009). Secondary 2 students' difficulties in solving non-routine problems. International Journal for Mathematics Teaching and Learning, 10, 1-30.

Zhang, P. (2010). Inference on students' problem solving performances through three case studies [Unpublished master's thesis].The Ohio State University, USA.

\section{Appendix 1. Sample items}

a) Tolga's team entered a mathematics contest where teams of students compete by answering questions that are worth either 3 points or 5 points. No partial credit is given. Tolga's team scored 44 points on 12 questions. How many 5 point questions did the team answer correctly? (Pre-test sixth problem)

b) The figure below consists of 9 rectangles. If 100 rectangles are used to create a similar shape, what will be the number of rectangles in the middle row? (Pre-test - seventh problem)

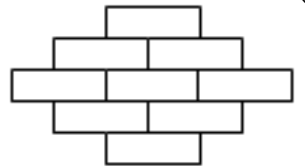

c) Choose four of the numbers 13, 5, 3, 7 and 11 so that their product is 1155 . (Post-test - fifth problem)

d) Mete makes shapes with matchsticks as follows. He needs 11 matchsticks to make 2 rows of shapes. He needs 21 matchsticks for 4 rows of shapes. How many matchsticks does he need to make 10 rows of shapes? (Post-test - eighth problem)<smiles>C1CCC2CCCCC2C1</smiles><smiles>C1CCC2CC3CC4CCCCC4CC3CC2C1</smiles> 